gangrene of the lung. Latterly profuse fetid expectoration became very marked, and the case was supposed to be one of acute phthisis. The lad attributed his illness to a piece of bone which had stuck in his throat seventeen months previously, from which time he had begun to cough, but his medical attendants did not adopt this view. After death, a piece of bone three-quarters of an inch by half an inch in size was found in the main bronchus of the left side, lying in an irregular and ulcerated cavity. The tissue of the left lung, which was adherent, was non-crepitant and leathery; there were cavities in every part. Dr. Broadhurst, in St. Mary's Hospital Reports (1880), relates the case of a weakly boy, fifteen years of age, subject to cough, and for three or four years previously affected with occasional attacks of hæmopystis. On Dec. 16th, 1879, he was seized with violent pain in the right side, aggravated by deep inspiration, with dulness on percussion; a very troublesome cough and expectoration of large quantities of muco-purulent sputum, quick pulse, and high temperature; then rigors. After improving a little, symptoms of peritonitis supervened, and he died on Feb. 6th. Post-mortem examination : Right lung was small, and contained a minute cavity; the bronchus was subdivided into a number of dilated cavities, and in one of these was found a fragment of a leguminous pod five-eighth by five-sixteenths of an inch; the bronchi were much thickened and dilated. There was extensive purulent peritonitis, and the liver was riddled with abscesses. Mr. Laver, at the Sheffield Medical and Chirurgical Society (Nov. 1877), mentioned the case of a boy in whom a piece of glass had entered the airpassages. Tracheotomy was performed, but the glass could not be found. He died about a month afterwards, and the glass was discovered in the right bronchus. Dr. Spitta reported a case in THE LANCET $(1876)$ in which a slate pencil completely plugged the left bronchus. The patient died of pneumonia on the eighth day. Instances of this nature might be multiplied indefinitely, all tending to show the greater or less danger resulting from the entrance of foreign bodies into the air-passages according to the different circumstances of the case, and, whatever the nature of the body may be, the fatal termination which sooner or late ensues if it cannot be got rid of. Moreover, that of all things there is none more dangerous than the dart which is employed in that popular and hitherto considered innocent game of "puff and dart." I am inclined to think that if such an instrument as was made for me (see Fig. 1 in THE LANCET of last week) had been available at an earlier period of Case 1 the result might have been different.

Edinburgh.

\section{THE BLUE-GUM STEAM TREATMENT OF INFECTIOUS DISEASES,}

Bx J. MURRAY GIBBES, M.B., C.M., \&c., CORONER, NEW PLYMOUTH, N.Z.

MY object in this paper is, first, to bring forward a treatment of diphtheria I have found very successful; and, secondly, to suggest that a similar treatment might possibly prove equally successful in other infectious diseases. The treatment is that of keeping the patient in an atmosphere of blue-gum (Euoalyptus globulus) steam. It is an acknowledged fact that in blue-gum we have a most perfect disinfectant; not an artificial one, but one of nature's own; one always at hand, for it will grow in temperate climates. The green leaves hung in a bedroom keep it sweet; leaves placed on a wound, steam inhaled from it, or its infusion drank, or injected into wounds, all answer equally well. Professor Lister speaks highly of the eucalyptus oil for wounds, and it is also spoken highly of in rheumatism. It has not an un pleasant smell, and is tolerated by nearly all. By infectious diseases, I mean those which are caused by micro-organisms. I think it is an established fact that typhoid fever, measles, small-pox, whooping cough, tuberculosis, scarlatina, \&c., are caused by fungoid growths. We know that they are introduced into the body by means of dust floating in the air, by milk, water, and food of all descriptions. After they have obtained entrance into the system, they multiply until they produce their specific effects. They pass out of the body in myriads, by means of the breath, per-

1 Read before the Taranaki Medical Association, October 4th, 1882. spiration, and discharges. Infection means the air being poisoned by these germs, and the incubation of a disease is the time required for their propagation into sufficient numbers to interfere with health, and that time seems to be lengthened or shortened according to the quantity introduced, the peculiarity of the different germs, or the state of the system at the time. That a specific germ can alone produce a specific disease is an established maxim It having been proved that certain germs produce certain diseases, the question arises, How can they be destroyed? Not only how we can cure the disease, but how can we pre vent it spreading? Say, for instance, we have a case of scarlatina in a town which had been free from that disease How can we prevent its spreading through the town? The answer, of course, would be isolation and disinfectants, and it would be perfectly correct, disinfectants having the power of destroying these germs. It is on this point I ask to draw attention-viz, the best and most effectual method of using disinfectants, so that the germs can be destroyed before they can do mischief. I stated that the breath, perspiration, and discharges coming from a patient suffering from an infectious disease are laden with germs all ready to do mischief. At the present time disinfectant lotions, gargles, sprays, and internal remedies are used, and disinfectants poured on the various discharges ; so far, so good, but the breath is laden with disease, and the evaporation of the perspiration also assists in poisoning the atmosphere of the room. Ventila. tion is then carried out to purify the room, but what becomes of the germs? They are dispersed into the external atmo sphere to carry disease to others in all directions, and here we come to the root of the matter. If we wish to stav epidemics from spreading, not only must we disinfect the discharges, but we must destroy every germ which comes from the bodv, either by the breath or otherwise, and to do this effectually we must keep the patient in a disinfected atmosphere. This must be done in every disease which is caused by micro-organisms, and until it is done we shall never be able to stay epidemics. It is the only true scientific method of dealing with disease. How is this best to be done? The discoveries made during the last few years and months revealed to me the cause of our many failures in curing these diseases, and the unscientific methods generally recommended. We gave remedies without having any idea how or why they cured disease; but now science has made vast strides and a great deal that was before obscure is being made plain; we have arrived at the root of the matter, and although, perhaps, we do not as yet know how they cause disease, yet we have a solid foundation to start from. Professor Lister revolutionised the treatment of wounds when he brought forward his grand treatment of operating in a disinfected atmosphere. "The germs cause disease, therefore keep them away" he said and the world bowed before his dictum feeling that he had hit the right nail on the head. If this answers in wounds, why should it not answer in infectious diseases?

After perusing the papers read before the International Congress, 1881, I felt convinced that the only efficient treatment of infectious diseases was to keep the patient in a dis. infected atmosphere for several days, and I had an opportunity of trying my treatment sooner than I expected, for in October of the same year an epidemic of diphtheria broke out in a township sixteen miles from here (New Plymouth Taranaki). ${ }^{2} \quad$ I had made for some years experiments with Eucalyptus globulus in various diseases with most satis. factory results, - namely, in leucorrhœa and other discharges, gonorrhoea, and so-called laryngeal phthisis, croup, bronchitis, \&c. My experience with disinfected steam has only been in the above epidemic, and the results have been most encouraging. Thirty-seven cases in which the treatment was carried out recovered without a bad sympiom, such as paralysis, without any medicine except castor-oil, and with. out stimulants, which disproves the statement that diph. theria requires a large quantity of alcohol. The disinfectant I used was made by pouring boiling water on blue-gum leaves. The patients were kept in the moist atmosphere for some days. I mopped the throat with dilute solution of perchloride of iron and glycerine every eight hours, and then covered the pharynx with porwdered sulphur. This I did in most cases, but the others recovered equally well. Two young ladies, aged seventeen and nineteen, coughed up complete casts of the large bronchi. An old lady, after I had mopped her throat once, refused to have it done; she had

: Published in the Australian Medical Gazette, Feb. 1882. 
a very dense patch behind and on the right tousil, the glands of her neck were very swollen and tender, the neck enlarged, and the breath was most offensive. On the third day half of the membrane had come away in small pieces, like grains of rice, the breath was sweet, and the swelling of the neck had nearly disappeared, and she made a perfect recovery. The epidemic was an unusually severe one, judged by the number of deaths of those who were treated by other means. The last cases which occured took place in two families closely allied, five children and their nurse being attacked. I attended two of the children (the first and last attacked) and the nurse. They recovered, whilst the other three, who were attended by a colleague, died. Local remedies are very good, but they are only a part of the treatment. We cannot perpetually keep spray applied to the throat, the children moving about from side to side of the bed. We must take the cure to them, and we can only do this by means of steam. My mode of procedure is very simple. I pour boiling water on blue-gum leaves, in a tub, jug, or chamber, which I place beside the bed, and change it every half hour. If only one child is ill in the room I improvise a tent over the bed, either by means of an open umbrella with a sheet above it, or by placing a sheet over the sides or ends of the bed, and enclose the patient. It is wonderful to see how soon the pain in the throat and the swelling disappear, and the fever also. Pain in the stomach is the first symptom most patients suffering from the malady experience, even before the throat is affected. At first I used a simple fever mixture; but I found it was not needed, as the skin acted more or less according to the amount of steam used. The patients were able to eat breadand-butter, the throat not being sore because I had not burnt it, as is the barbarous treatment recommended by some. In diphtheria the throat is never very sore unless caustics are applied. In simple cases of it many remedies will answer ; but if it once gets to the larynx and below it no remedy can touch it except steam. The laryngoscope showed patches on the vocal cords, and the breathing that it had extended lower ; and in some cases where suffocation seemed imminent the distressing symptoms would be suddenly relieved by the membrane being coughed up. One young lady remarked, "The steam saved my life."

Although blue-gum steam has answered so well with me, it is not the remedy alone that I wish to bring before the profession, but the principle of the treatment, feeling sure that when a thorough trial has been given to it no other treatment would be found to give such satisfactory results and if it answers in diphtheria it would answer equally well in other infectious diseases. In typhoid fever the heat would be lessened, the skin kept moist, and the bowels would not have to do double duty. In pertussis it would allay the irritation of the bronchial mucous membrane in the same way that it does in bronchitis, croup, and asthma. In scarlatina the congestion of the pharynx and the skin would be relieved. In so-called laryngeal phthisis it has given most satisfactory results. In influenza the infusion of Eucalyptus globulus is a very popular remedy, and it is one of the most infectious diseases. If blue-gum steam were adopted as a disinfectant, or any other drug, in the ward of a hospital, I should have a boiler outside, with pipes leading into the ward along the floor, with small holes in them to allow the steam to pass through, and have a stopcock at the commencement to regulate the amount of steam. A pipe conld also be placed along the wall, with mouth-pieces attached, for those patients who suffered from throat affections. The boiler could be placed in a sand bath, so as to regulate the heat of the water, or a gas stove used. The leaves could be placed in a net in the water, and changed as often as required. The advantages of the blue-gum steam treatment are that it can be used by ordinary attendants ; in fact, a farmer at Tikorangi treated seven cases and cured them. In one of these cases, he informed me, the membrane returned again and again for three weeks. He trusted entirely to the blue-gum steam. No internal remedies are required. New Plymouth, Taranaki, N.t.

Presentation. - On the occasion of the removal of Mr, Jessett, F.R.C.S. Eng, from Erith, to take up his residence in London, a testimonial, consisting of a handsome hall chiming clock, a vase on stand, and an illuminated address, was presented to him by a number of friends and parients in the first-named locality.

\section{THE CASE (ACUTE DIABETES) OF POLICE CONSTABLE SANSOM.}

By W. WANSBROUGH JONES, M.B. OXON,, \&c, HOUSE PHYSICIAN, ST. THOMAS'S hOSPITAL.

THE main facts relating to the death of Police Constable Sansom have already been recorded in the columns of THE LANCET; I purpose here adding only the few clinical details obtained during his short stay in hospital.

It will be remembered that on the evening of Sunday, December 24th, he complained of feeling unwell for the first time during the two years he had been in the police force. He felt aching pains in his limbs, and too weak to do his eight hours' duty. He managed, however, to get through it, but broke down during the Monday night. On Tuesday night he was not allowed to go on duty, but sent to bed by the deputy divisional surgeon. On the Wednesday he was once a little delirious. On Thursday he seemed weak and ill, but Dr. Blades was unable to arrive at a diagnosis after going fully into the case. The urine he was unable to obtain for analysis. On the Friday morning he became semi-comatose and very collapsed, and in this condition was admitted into St. Thomas's Hospital under the care of Dr. Bristowe. Some simple restoratives were administered, and in about three-quarters of an hour he was seen by Dr. Bristowe. He was then sufficiently conscious to answer questions asked in a very loud tone of voice. He said he was not in pain. and though he answered questions put to him intelligently, very little could be gathered as to his condition. The policeman who had been taking care of him could give very little information about him, excepting that he had passed water frequently during the night. The result of a careful physical examination was equally unsatisfactory. The skin was dry; the tongue slightly furred and dry. He was thin, but not emaciated. The temperature was normal. The pupils of moderate size, equal, and reacting to light. The lungs in front, the heart, and abdomen seemed natural. There was no cdema of the limbs, and no sign of paralysis. Dr. Bristowe therefore thought that the man was either suf. fering from uræmia or in a state of diabetic coma. As no water was voided during the first four hours after admission a catheter was passed, and four ounces of urine drawn off. The temperature rose, the breathing became quicker and the coma more profound, and in the course of the next hour he died. Half an hour before death the temperature was $103^{\circ}$; half an hour after death it was $105^{\circ}$.

A post-mortem examination was made on Saturday afternoon. All the viscera, including the nervous centres, were congested, and the brain seemed to have the sweet odour which is said to be characteristic of diabetes. The congestion was recent, and was in all probability due to the feeble action of the heart for some hours before death.

Remarks.-The great difficulty and obscurity of the case will be at once apparent when it is noticed that neither the examination made before death nor that after death afforded any satisfactory explanation of the patient's condition. In fact if the few ounces of urine mentioned above had not been obtained the case might still remain a mystery. This urine was of high specitic gravity-1040, acid reaction, and contained a large quantity of sugar and some albumen. No medical man looking at the whole of these facts could for one moment doubt the nature of Police Constable Sansom's malady. Nor is there anything peculiar in the sequence of events. The diabetes ran its usual course. But it was a most unusually rapid course. Diabetes is usually a very chronic disease, which kills the patient by gradually exhausting him until he falls into a comatose state, or dies of phtbisis. Cases of so-called acute diabetes are very rare, and probably several of the cases so classified if thoroughly looked into would prove to be cases in which the disease had been existing unrtcoonised for some time, but in which some acute exacerbation had brought symptoms into prominence which led to a diagnosis. There are several cases on record in which death has resulted in two or three weeks from the first recognition, it may be the first onset of the disease. But a case of only five days' duration in a man apparently quite healthy before is to us at any rate quite unprecedented. 